\title{
Ensembles of AGCM Two-Tier Predictions and Simulations of the Circulation Anomalies during Winter 1997-98
}

\author{
John D. Farrara, Carlos R. Mechoso, and Andrew W. Robertson \\ Department of Atmospheric Sciences, University of California, Los Angeles, Los Angeles, California
}

(Manuscript received 9 August 1999, in final form 11 January 2000)

\begin{abstract}
The impact of sea surface temperature (SST) anomalies on the extratropical circulation during the El Niño winter of 1997-98 is studied through atmospheric general circulation model (AGCM) integrations. The model's midlatitude response is found to be very robust, of the correct amplitude, and to have a fairly realistic spatial structure. The sensitivity of the results to different aspects of the anomalous distributions of SST is analyzed. It is found that the extratropical circulation in the North Pacific-North American sector is significantly different if SST anomalies over the Indian Ocean are included. Using a comparison of observed and simulated 200-hPa streamfunction anomalies, it is argued that the modeled midlatitude impact of Indian Ocean SST anomalies is largely realistic. However, while the local sensitivity of the atmosphere to small differences in SST anomalies in the tropical Pacific can be substantial, the remote sensitivity in midlatitudes is small. Consistently, there is little difference between the simulated extratropical circulation anomalies obtained using SSTs predicted by the National Centers for Environmental Prediction in October 1997 and those obtained using observed tropical Pacific SSTs. Neither is there any detectable atmospheric signal associated with SST anomalies over the North Pacific.

Analyses of the results presented here suggest that the influence of SST anomalies in the Pacific and Indian Oceans during the selected ENSO event can be interpreted as the quasi-linear superposition of Rossby wave trains emanating from the subtropics of each ocean. An inspection of intraseasonal weather regimes suggests that the influence of tropical SST anomalies can also be described as a shift in the frequency of occurrence of the model's modes of intrinsic variability and a change in their amplitude. These findings suggest the potential utility of SST forecasts for the tropical Indian Ocean.
\end{abstract}

\section{Introduction}

The predictability of El Niño and its remote impacts is a subject of intense current interest. In midlatitudes, El Niño events tend to be accompanied by a deepened Aleutian low and a ridge downstream over North America (Horel and Wallace 1981). This wavelike pattern resembles the classical Pacific-North American (PNA) teleconnection pattern (Wallace and Gutzler 1981), or more precisely the tropical Northern Hemisphere (TNH) pattern (Barnston and Livezey 1987; Deser and Blackmon 1993; Robertson and Ghil 1999). There is, however, considerable inter-El Niño variability in the observed response patterns (Kumar and Hoerling 1997) and the relationship between tropical SST anomalies and TNH-like patterns is still not well understood (Ting and Sardeshmukh 1993; Kumar and Hoerling 1995). Nevertheless, there is mounting evidence that intense El

Corresponding author address: Dr. John D. Farrara, Department of Atmospheric Sciences, University of California, Los Angeles, Los Angeles, CA 90095-1565.

E-mail: jfarrara@ucla.edu
Niños such as the 1982-83 and 1997-98 events exert a large and robust influence on the midlatitude atmosphere (Barnett and Preisendorfer 1987; Palmer and Anderson 1994; Brankovic et al. 1994; Kumar and Hoerling 1997; Barnston et al. 1999).

Two-tier seasonal-to-interannual prediction systems (Bengtsson et al. 1993; Barnett et al. 1994; Ji et al. 1994) use a coupled ocean-atmosphere GCM to predict SSTs, which are then prescribed as the boundary conditions for ensembles of atmospheric GCM (AGCM) "predictions." These produce a prediction of the extratropical response and assessment of its statistical significance. It is important to know the limitations of this approach: which aspects of the global SST distribution need to be captured, and how accurately, in order to make successful two-tier predictions? Do small SST errors over the tropical Pacific have a measurable impact on the extratropical response of an AGCM? Do the SST anomalies (SSTAs) over other oceans-the Indian, Atlantic, and extratropical Pacific Oceans-that tend to accompany El Niño events have any significant impact? These questions are not completely resolved. As an example, consider the influence of SST anomalies over the extratropical North Pacific. A number of AGCM 
studies (e.g., Saravanan 1998; Lau 1997; Graham et al. 1994) have shown that the atmospheric response to midlatitude SST anomalies is weak and not very robust. However, a somewhat more robust response has been found in models with higher spatial resolution (Ferranti et al. 1994; Latif and Barnett 1994). Furthermore, using an analysis of observational data, Gershunov and Barnett (1998) recently argued that the relatively modest $(<1 \mathrm{~K})$ SST variations in the extratropical Pacific Ocean associated with the North Pacific oscillation can have a substantial impact on the extratropical response to El Niño and La Niña.

The present paper examines the atmospheric response to SST anomalies during the exceptional ENSO event that developed in 1997-1998. This event was characterized by strong SST anomalies in the Pacific-some of the strongest on record-starting as early as the northern spring of 1997. Significant SST anomalies also developed in the Indian Ocean, and extratropical Pacific; the positive anomalies in the western Indian Ocean were the largest ever observed there. We focus on the January-March (JFM) 1998 seasonal circulation and precipitation anomalies. The choice of JFM averages rather than December-February (DJF) averages as representative of the northern winter was based on the greater similarity among the anomaly patterns (especially in the extratropics) in individual months during these three months than during DJF. To address the importance of different aspects of the SST distribution we examine separately the impact of SST anomalies in the tropical Pacific, extratropical Pacific, tropical Indian, and tropical Atlantic Oceans.

The most striking aspect of our results is the significant sensitivity of the model's extratropical response to the SST anomalies in the Indian Ocean. In order to interpret this result, we test the extent to which the extratropical response to SST anomalies confined to the tropical Pacific and Indian Oceans can be simply estimated by linear superposition of the individual responses. Linear theory has been used very successfully in describing the main features of the extratropical response to El Niño. The great circle stationary Rossby wave train that arises when an equatorial heat source is specified in a zonally symmetric linear model (Hoskins and Karoly 1981) clearly resembles the PNA-TNH pattern. The linear response becomes even more realistic when climatological stationary waves are included in the basic state (Branstator 1992; Ting and Yu 1998).

We also test the extent to which the model response and its sensitivity to the region of SST forcing can be accounted for by the differential excitation of intrinsic modes of the model. This is done through an empirical analysis of intraseasonal weather regimes. In this case, the response becomes closely related to the modes of instability of the midlatitude atmosphere (Branstator 1985). Nonlinearity associated with the transient eddies may also be important (Held et al. 1989).

We begin in section 2 with a description of the model and of the design of the simulations and predictions. In section 3 we compare observed tropical precipitation anomalies, and extratropical circulation and precipitation anomalies with those simulated and predicted. Section 4 contains a discussion and interpretation of the significant impact we find of Indian Ocean SSTs on the extratropical circulation in the ensembles that include them. We conclude with a summary of findings in section 5 .

\section{Model and simulations}

We use the University of California, Los Angeles, AGCM, which includes advanced parameterizations of the major physical processes in the atmosphere including solar and terrestrial radiation (Harshvardhan et al. 1987, 1989), cumulus convection and planetary boundary layer (PBL) processes. The parameterization of cumulus convection is a version of the Arakawa-Schubert scheme (Arakawa and Schubert 1974) in which the cloud work function quasi-equilibrium assumption is relaxed by predicting the cloud-scale kinetic energy (Pan and Randall 1998). PBL processes are parameterized using the mixed-layer approach of Suarez et al. (1983) as recently revised by Li and Arakawa (1997); these modifications result in much improved surface latent heat fluxes and stratocumulus cloud incidence. A more detailed description of the model can be found in Mechoso et al. (2000), as well as online (http:// www.atmos.ucla.edu/esm/agcmdir). For this investigation, we select the $2.5^{\circ}$ longitude by $2^{\circ}$ latitude, 29-layer version with a domain extending from the earth's surface to the top of the stratosphere $(1 \mathrm{hPa})$.

The integrations performed cover the period 1 October-31 March. The initial conditions were obtained by adding small random perturbations to the model's prognostic variables corresponding to an atmospheric state in early northern fall. This base atmospheric state was constructed using observational data corresponding to 1 October 1982. An eighteen-member control ensemble (control) was performed using Global Sea-Ice and Sea Surface Temperature Data Set climatological SSTs (Rayner et al. 1995). Six additional nine-member ensembles were each performed with different distributions of SST anomalies added to the climatological fields. The choice of nine-member ensembles was partly guided by the suggestion of Kumar and Hoerling (1995) that an AGCM ensemble size of 6-10 should be sufficient to reliably detect the extratropical atmospheric response to SST forcing. The distribution type is used to identify the integrations. The "forecast" uses the SST anomalies in the tropical Pacific $\left(30^{\circ} \mathrm{S}-25^{\circ} \mathrm{N}, 120^{\circ}\right.$ $290^{\circ} \mathrm{E}$ ) from the ensemble of predictions completed on 15 October 1997 using the National Centers for Environmental Prediction (NCEP) coupled atmosphereocean GCM (Ji et al. 1998). The "tropical Pacific" experiment uses observed anomalies (Reynolds and Smith 1995) in the same tropical Pacific domain in which they 
Sea Surface Temperatures - JFM 1998
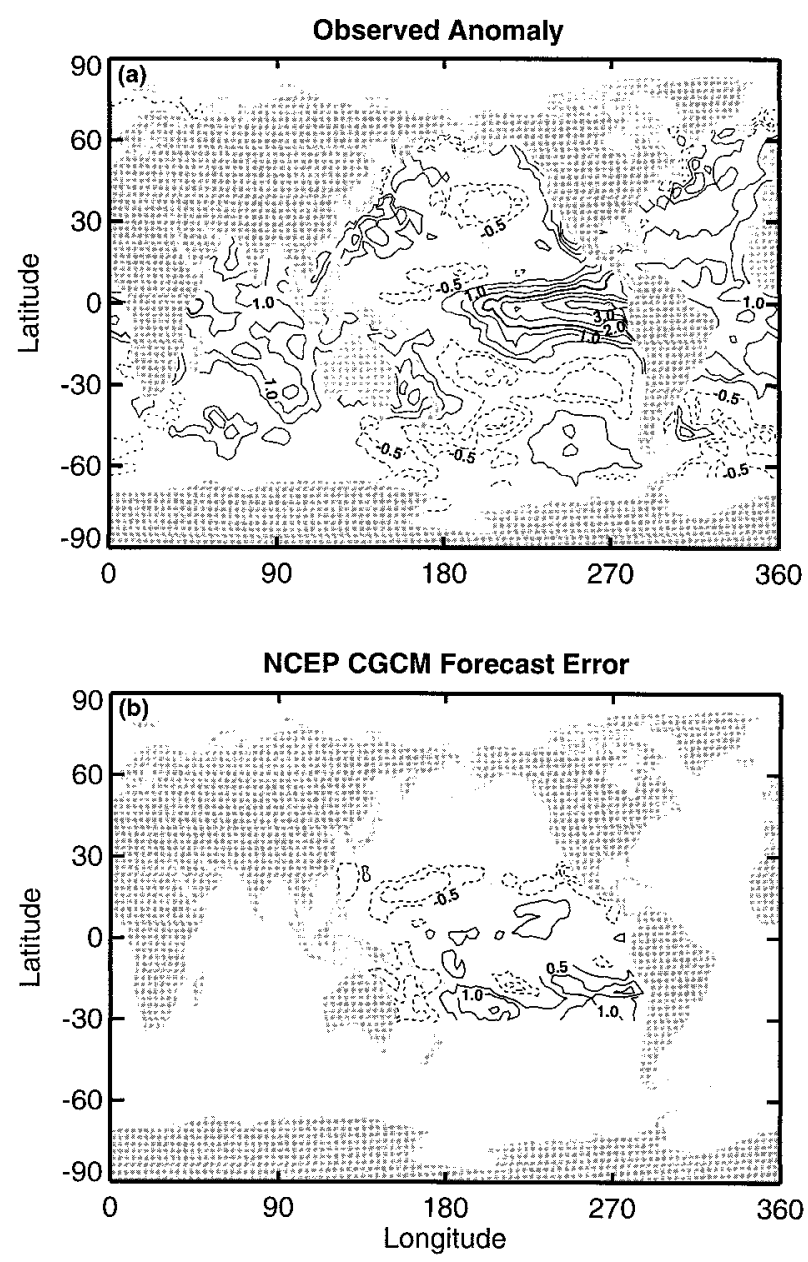

FIG. 1. (a) Mean observed global sea surface temperature anomalies (K) for the period Jan-Mar 1998. The contour interval is $0.5 \mathrm{~K}$ (zero contour omitted, $2-\mathrm{K}$ contour bold) and negative values are shown with dashed contours. (b) The difference between the anomalies in (a) and those predicted by the NCEP coupled GCM and used to force the forecast experiment. The contour interval is $0.5^{\circ} \mathrm{K}$ and negative values are shown with dashed contours.

were predicted by the NCEP coupled GCM. The "Pacific" experiment uses observed anomalies for the entire Pacific basin $\left(65^{\circ} \mathrm{S}-65^{\circ} \mathrm{N}, 120^{\circ}-290^{\circ} \mathrm{E}\right)$. The "Pacific+Indian" experiment uses observed anomalies in the Indian Ocean $\left(65^{\circ} \mathrm{S}-25^{\circ} \mathrm{N}, 40^{\circ}-120^{\circ} \mathrm{E}\right)$ in addition to those in the Pacific experiment. The "global" experiment uses observed anomalies in all ocean basins. Finally, the "Indian" experiment uses observed anomalies in the Indian Ocean only. To assess the statistical significance of our results we apply a standard Student's $t$-test.

Figure 1a shows the observed SST anomalies averaged over the period January-March 1998. The dominant feature in this field is the area of large positive values in the central and eastern tropical Pacific indicative of a strong El Niño. There are also significant positive anomalies (locally greater than $2^{\circ} \mathrm{C}$ ) in the Indian Ocean and tropical Atlantic, and weaker negative anomalies in the western tropical Pacific and the midlatitude North and South Pacific as well as in the South Atlantic. Warm anomalies in the tropical Indian Ocean frequently accompany strong warm anomalies in the eastern tropical Pacific, although a clear cause and effect relationship has yet to be demonstrated (Tourre and White 1995). Klein et al. (1999) present evidence that SST anomalies in the tropical Indian Ocean are connected to those in the tropical eastern Pacific Ocean through associated adjustments in the tropical atmospheric circulation, which they termed a "tropical atmospheric bridge."

Figure $1 b$ shows the errors of NCEP-predicted (at a lead time of 5 months) tropical Pacific SSTs. The prediction is very accurate: errors are less than $1 \mathrm{~K}$ within $10^{\circ}$ of the equator. Near the northwestern and southwestern boundaries are errors that exceed $1 \mathrm{~K}$; along the northern boundary predicted SSTs are cooler than that threshold and along the southern boundary they are warmer.

\section{Predicted and simulated responses to SST anomalies}

In this section, modeled atmospheric anomalies are defined as the difference between the ensemble means of a particular integration with SST anomalies and the 18-member ensemble mean of control, which uses climatological SSTs. In the context of a case study, it is appropriate to compare the response to a prescribed distribution of SST anomalies with a climatological control run, in which the SST anomalies are absent. Our null hypothesis here is that SST anomalies do not influence the atmosphere and that all variability is intrinsic to the atmosphere. The consideration of any nonlinearities in which SST anomalies exert a rectified influence on the model climatology (e.g., Robertson et al. 2000) is beyond the scope of this study. Control simulations using climatological SSTs have been used by many authors over the years (e.g., Sud et al. 1991; Atlas et al. 1993; Chiba et al. 1996; Kirchner et al. 1998) in case studies of the impact of different lower boundary processes (such as SST distributions, soil moisture, deforestation, and snow cover) on the simulated atmospheric circulation.

\section{a. Tropical response to SST anomalies}

The first link in the chain that determines the remote response to tropical SSTs is established through the relationship between SST anomalies and overlying latent heating anomalies in the Tropics. Figure 2 shows JFM 1998 precipitation anomalies (an excellent proxy for vertically averaged latent heating anomalies) between $30^{\circ} \mathrm{S}$ and $30^{\circ} \mathrm{N}$ from observations [estimates from the Climate Prediction Center merged analysis of precipi- 

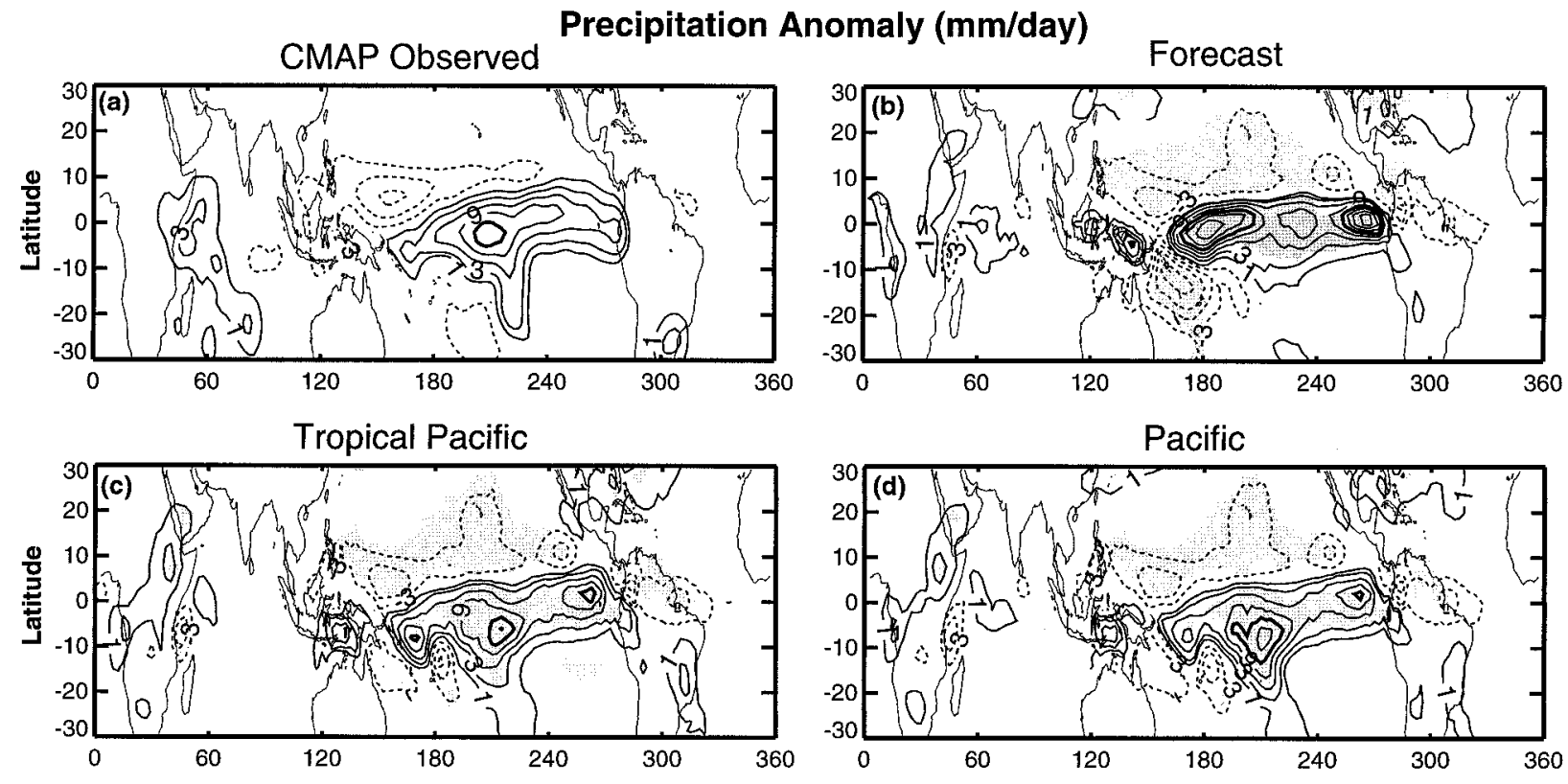

Pacific+Indian
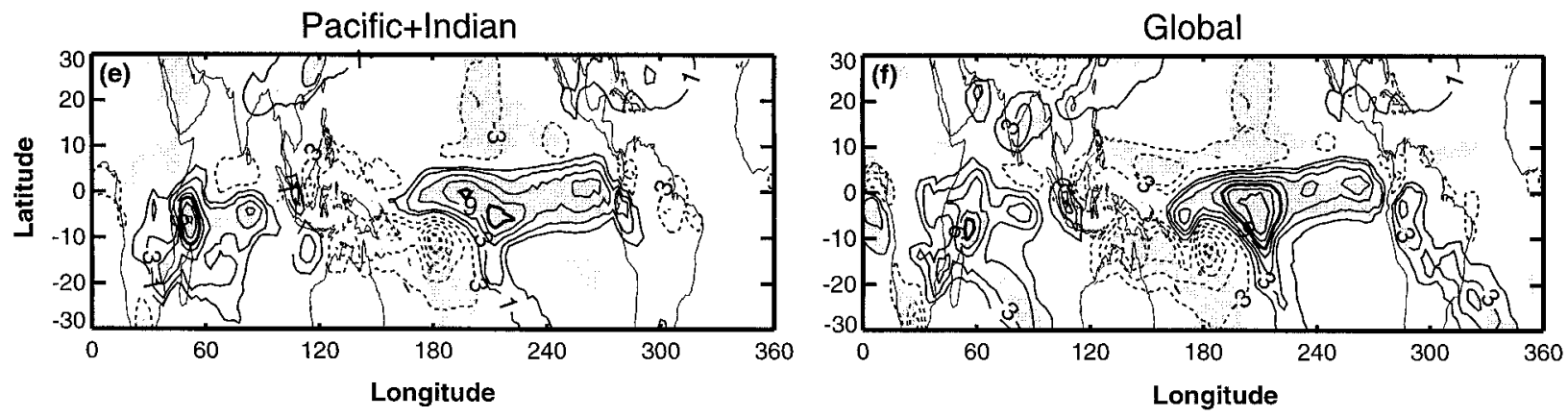

FIG. 2. Jan-Mar 1998 mean tropical precipitation anomalies $\left(\mathrm{mm} \mathrm{day}^{-1}\right)$. The contour interval is $3 \mathrm{~mm} \mathrm{day}^{-1}$ (zero contour omitted), negative values are shown with dashed contours, and the $12 \mathrm{~mm}$ day ${ }^{-1}$ contour is bold. An additional contour has been drawn at $1 \mathrm{~mm}$ day $^{-1}$. Anomalies shown are from (a) CMAP observations (Xie and Arkin 1997), (b) the forecast experiment, (c) the tropical Pacific experiment, (d) the Pacific experiment, (e) the Pacific+Indian experiment, and (f) the global experiment. (b)-(f) Shaded areas denote anomalies that are significant at the $99 \%$ level.

tation (CMAP); Xie and Arkin (1997)], the forecast, and the different experiments. In the Pacific basin, the observations show large positive anomalies straddling the equator from the date line to the coast of Peru. The largest values $\left(>12 \mathrm{~mm} \mathrm{day}^{-1}\right)$ are centered at the equator and $210^{\circ} \mathrm{E}$. At approximately the same longitude the region of positive anomalies extends southeastward into the southern subtropics. There are smaller positive anomalies (peak values of slightly more than $3 \mathrm{~mm}$ day $^{-1}$ ) over the western equatorial Indian Ocean (Fig. 2a), which also extend toward the southeast into the subtropics. The primary negative anomalies are located in the western Pacific between the equator and $10^{\circ} \mathrm{N}$ with weaker negative anomalies throughout the rest of the western Pacific, including the region of the South Pacific convergence zone (SPCZ), and in the eastern Indian Ocean.

The regions of positive precipitation anomalies in Fig. 2a broadly coincide with those of positive SST anom- alies in Fig. 1. Specifically, there is a coincidence of positive precipitation and SST anomalies in the equatorial Pacific east of the date line, including a southeastward extension (less noticeable in SST) around $210^{\circ} \mathrm{E}$, and in the western Indian Ocean where positive anomalies extend from near the equator and $60^{\circ} \mathrm{E}$ southeastward into the subtropics. Such a coincidence is common in the tropical Pacific, but relatively rare in the Indian Ocean where the observed correlation between interannual variations in precipitation and SST is quite low (Kumar and Hoerling 1998). This suggests that normally the influence of the tropical Pacific (via the tropical atmospheric bridge) dominates. During 1997-98, however, we speculate that the Indian Ocean SST anomalies were large enough to overcome this effect. We note that there is generally less coincidence between negative precipitation anomalies and negative SST anomalies, especially in the Indian Ocean.

Except for small regions in Central and South Amer- 
ica and the extreme southeastern United States, statistically significant (at the $99 \%$ level) precipitation anomalies in the forecast are confined to the Pacific basin, which is the only region where anomalous SSTs are prescribed (Fig. 2b). In the Pacific, the large positive anomalies are stronger $\left(>8 \mathrm{~mm} \mathrm{day}^{-1}\right)$ and are centered slightly farther north than observed. Furthermore, the positive anomalies extend farther west into the western Pacific than observed. In most of this region, these positive anomalies are highly statistically significant. There are statistically significant negative anomalies in the western Pacific just north and south of the equator as were observed, although their magnitude in the region of the SPCZ is larger than that observed. In addition, the observed extension into the subtropics of the positive anomalies near $210^{\circ} \mathrm{E}$ is not found. This suggests a sensitivity of tropical precipitation to details in the distribution of tropical SSTs.

Figures $2 \mathrm{c}$ and $2 \mathrm{~d}$ show the precipitation anomalies obtained in the tropical Pacific and Pacific experiments. As in the forecast, the statistically significant anomalies are practically confined to the Pacific Ocean basin. The pattern and magnitude of the anomalies in this region are closer to those observed in both the experiments than in the forecast. This is another example we find of the sensitivity of tropical precipitation to tropical SST anomalies. The differences between the tropical Pacific (Fig. 2c) and Pacific experiments (Fig. 2d) are much smaller than the differences between either and the forecast. Including SST anomalies outside the Pacific does not substantially change the simulated tropical precipitation in the Pacific except in the region of the SPCZ, where the negative anomalies are stronger (see Figs. 2e and 2f). There are, however, statistically significant precipitation anomalies in regions outside the Pacific in these two experiments. Those in the far western Indian Ocean, which extend southeastward into the subtropics and are associated with the larger SST anomalies, are most prominent. These precipitation anomalies are similar in location to the observed (Fig. 2a), but their magnitude is substantially overestimated (somewhat less so in the global than in the Pacific+Indian experiment, though the difference is not statistically significant).

\section{b. Midlatitude response}

We examine first the JFM 1998 anomalies in 700-hPa heights from the observations [data from the NCEPNCAR 40-Year Reanalysis; Kalnay et al. (1996)] and each of the experiments (see Fig. 3). The observed anomalies are calculated by taking the difference between reanalysis fields for 1998 and those averaged for the years 1968-96 as the observed climatology. As in previous figures, gray shading denotes regions where values are statistically significant at the $99 \%$ level. The largest observed anomalies are in the North PacificNorth America sector. They are broadly characterized by strong negative values in the midlatitude Pacific ex- tending eastward across the southern United States, large positive values over much of Canada, and small positive values in the subtropical Pacific. The observed negative anomaly center in the Pacific is centered at approximately $45^{\circ} \mathrm{N}$ and $140^{\circ} \mathrm{W}$ and positive anomalies are centered over eastern Canada. The largest negative anomalies in the Pacific are about $110 \mathrm{~m}$ and the largest positive anomalies over Canada are about $70 \mathrm{~m}$.

The forecast, as well as the Tropical Pacific and Pacific experiments, all show similar $700-\mathrm{hPa}$ height anomaly patterns, with a highly statistically significant negative anomaly center slightly west of that observed (near $45^{\circ} \mathrm{N}$ and $165^{\circ} \mathrm{W}$ ) and positive anomalies covering all of Canada and Alaska. Positive anomalies were observed across much of Canada, but observed anomalies were negative over Alaska. The positive anomalies are statistically significant in a large region only in the forecast. The maximum amplitudes of the simulated negative and positive anomalies in the eastern Pacific and Canada are within $20 \mathrm{~m}$ of the observed anomaly amplitudes in these regions $(-100$ and $+60 \mathrm{~m}$, respectively). Neither the differences between the anomalies in the tropical Pacific and Pacific experiments (not shown) nor the differences between the forecast and the tropical Pacific experiment (not shown) are statistically significant. Thus, although the tropical precipitation patterns are not identical, there is no detectable extratropical signal associated with either difference in the structure and evolution of tropical Pacific SSTs or midlatitude SSTs. These results, which were obtained with a relatively high spatial resolution, support the notion that the atmospheric response to midlatitude SST anomalies is, at the very least, nonrobust (Lau 1997).

The Pacific+Indian and global experiments (Figs. 3e and 3f) show a pattern of anomalies that differs substantially from the others. The negative anomaly center in the North Pacific is located farther north and east (near $55^{\circ} \mathrm{N}, 150^{\circ} \mathrm{W}$ ) and positive anomalies are confined to eastern Canada. Anomalies in both these centers are highly statistically significant and the simulated maximum amplitude is within $20 \mathrm{~m}$ of that observed. The positive anomalies in the subtropical Pacific Ocean are somewhat overestimated, however. Figure 4 shows the differences in $700-\mathrm{hPa}$ heights between the Pacific + Indian and Pacific experiments. These are significant over much of the midlatitude Pacific and large parts of North America. The marked differences between the circulation anomalies over the North Pacific-North America sector in these experiments suggest an important impact of the SST anomalies in the Indian Ocean. The hint of a similar sort of impact can be seen in the difference between Figs. 4a and 4b of Lau (1997), which show composite 500-hPa height anomalies for a set of El Niños. His Fig. 4a is obtained from GCM integrations using global SST anomalies for several ENSO warm events, while in his Fig. 4b only tropical Pacific SST anomalies are used. We note that in his Fig. 4a positive anomalies in the central subtropical Pacific are more 
700 mb Geopotential Height Anomalies (m)

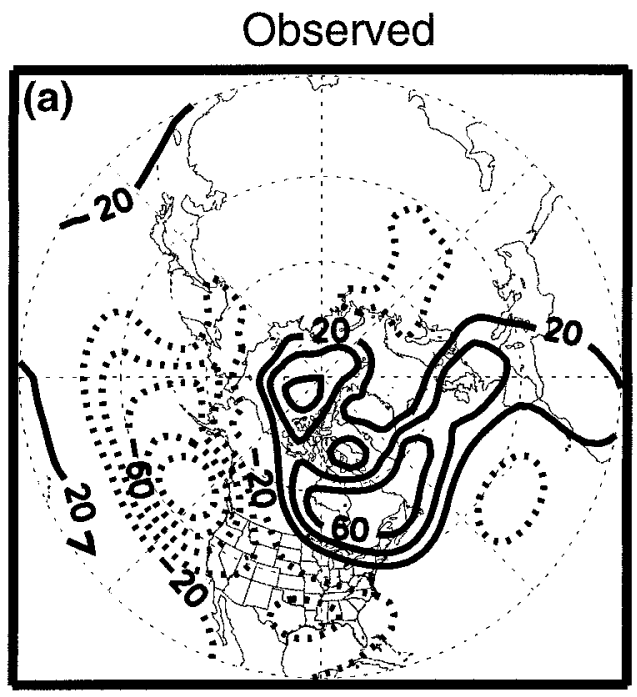

Forecast

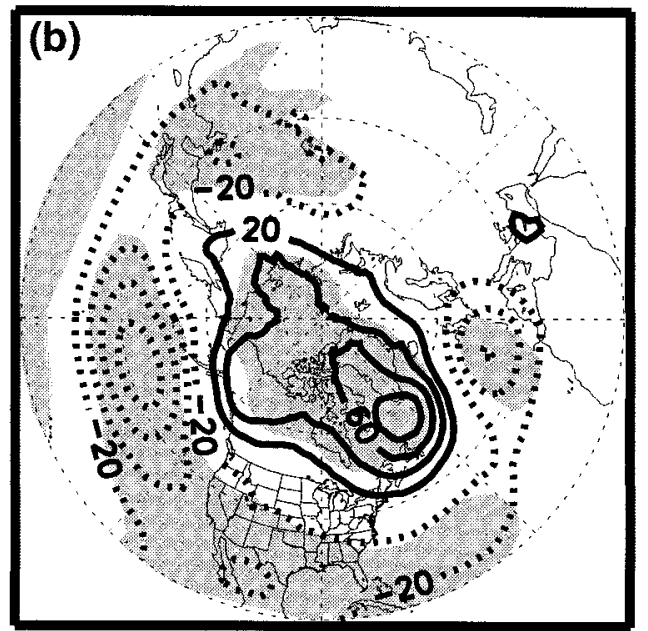

Tropical Pacific

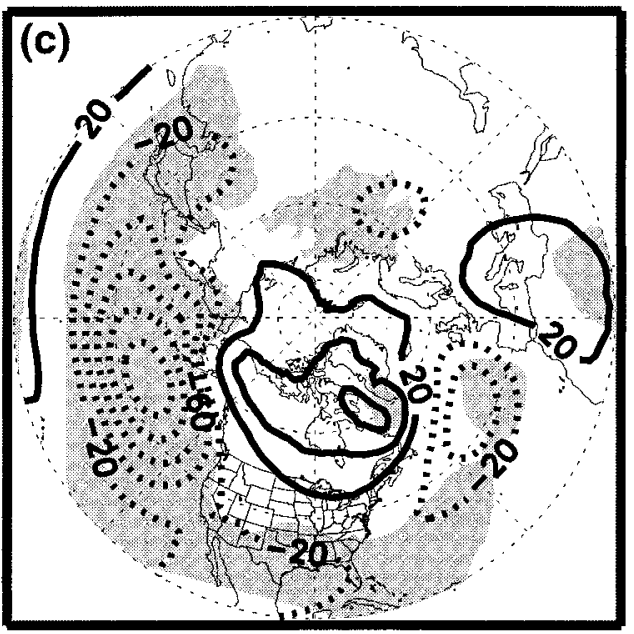

Pacific+Indian

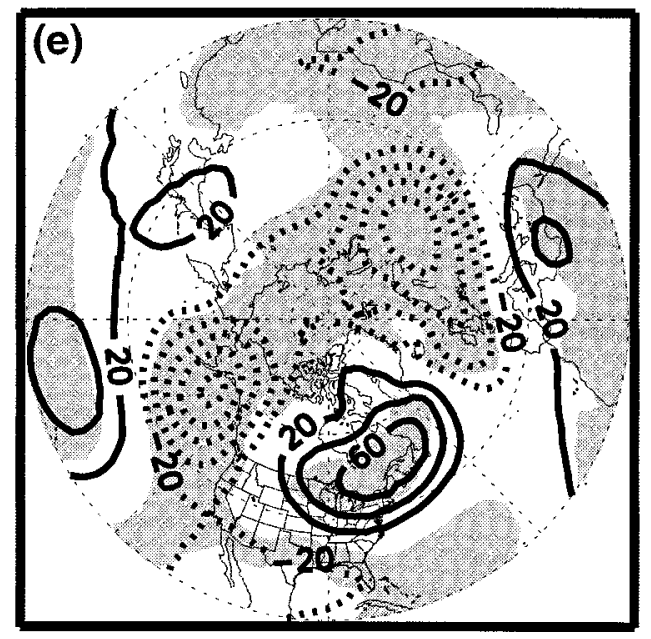

\section{Pacific}

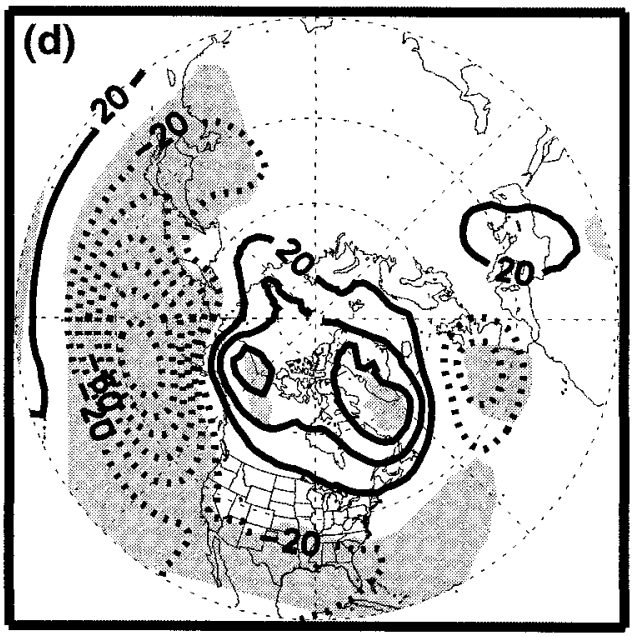

Global

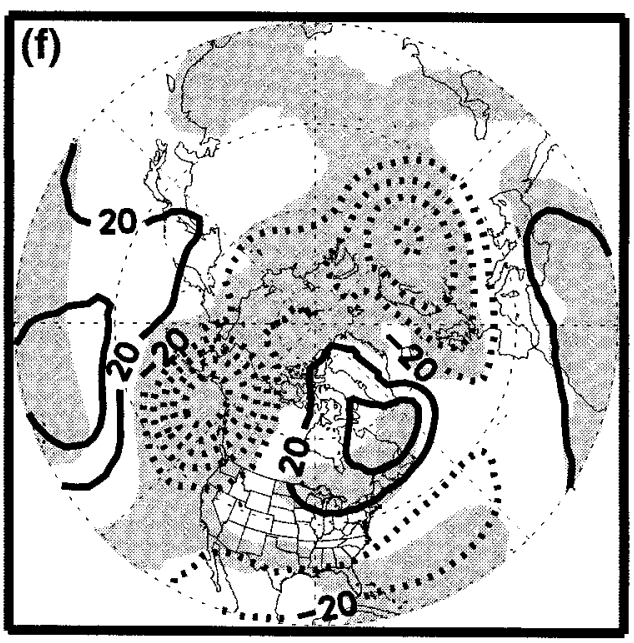




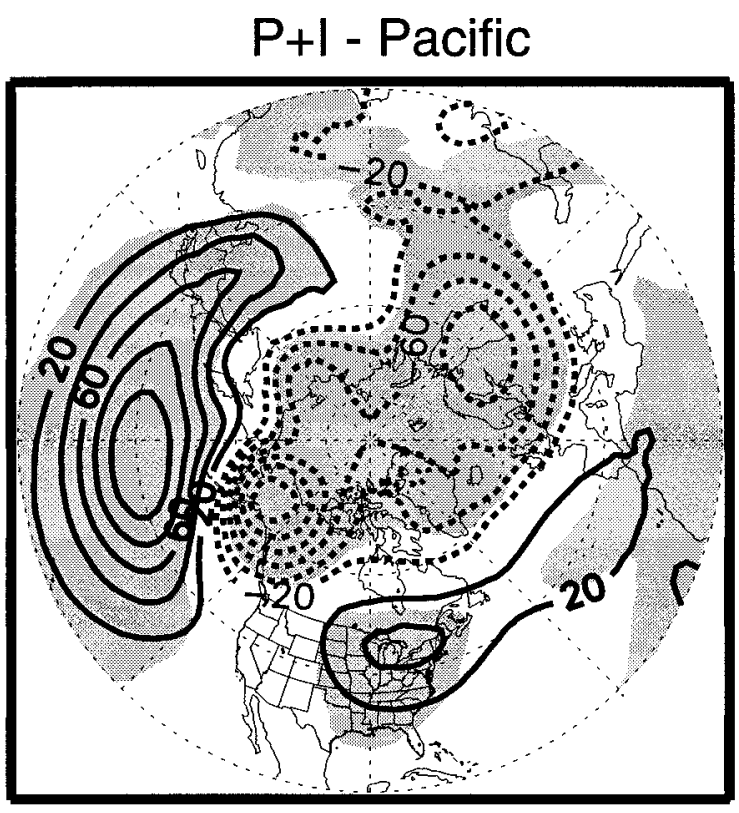

FIG. 4. Difference in mean 700-hPa geopotential height anomalies (m) for the period Jan-Mar 1998 between the Pacific +Indian and the Pacific experiments. Contour interval is $20 \mathrm{~m}$ (zero contour omitted), negative values are shown with dashed contours, and shaded areas denote anomalies that are significant at the $99 \%$ level.

pronounced than in Fig. $4 \mathrm{~b}$ and anomalies are predominantly negative over Alaska in Fig. 4a, while they are predominantly positive in Fig. 4b. These are the same sort of differences that are seen when comparing Fig. $3 e$ to $3 c$, and which we attribute to Indian Ocean SST anomalies. However, as noted in the previous section, precipitation anomalies in the tropical Indian Ocean are overestimated in the Pacific+Indian and global experiments. We will address this issue in section $4 \mathrm{~b}$.

In the absence of a long "control" run that uses observed SSTs, a detailed analysis of the skill of the FORECAST and experiment runs cannot be undertaken. In the following the term "skill" is used as a measure of model performance in a particular case and is not meant to imply any predictive skill. The skill of the anomaly fields produced by the different experiments has been compared using anomaly correlations (Murphy and Epstein 1989) between simulated and observed JFM $700-\mathrm{hPa}$ heights for the region from $20^{\circ}-70^{\circ} \mathrm{N}$ and $180^{\circ}$ $300^{\circ} \mathrm{E}$ (see Table 1). The Pacific + Indian experiment has the highest anomaly correlation (0.79), and the forecast has the lowest (0.56), with the rest of the experiments clustered in a range of values that is slightly smaller than that of the Pacific + Indian. However, as can be seen
TABLE 1. Anomaly correlation: JFM 1998 700-hPa geopotential heights.

\begin{tabular}{|c|c|c|}
\hline Experiment & $\begin{array}{c}\text { Anomaly correlation } \\
20^{\circ}-70^{\circ} \mathrm{N}, 180^{\circ}-300^{\circ} \mathrm{E}\end{array}$ & $\begin{array}{c}\text { Correlation } \\
\text { between } \\
\text { ensemble mem- } \\
\text { bers and } \\
\text { ensemble mean }\end{array}$ \\
\hline Forecast & $0.56 \pm 0.07$ & 0.85 \\
\hline Tropical Pacific & $0.72 \pm 0.08$ & 0.82 \\
\hline Pacific & $0.68 \pm 0.09$ & 0.81 \\
\hline Pacific + Indian & $0.79 \pm 0.08$ & 0.88 \\
\hline Global & $0.73 \pm 0.08$ & 0.86 \\
\hline
\end{tabular}

from the error bars in Table 1, we cannot clearly distinguish between the skill of the different experiments. Thus, we cannot be certain whether the significantly different anomaly pattern obtained when Indian Ocean SST anomalies are included is really an improvement. The forecast, however, is somewhat less skillful than any of the experiments. Also shown in Table 1 is the average spatial correlation between the ensemble mean anomaly pattern and that of the individual members of each ensemble. These correlations are high $(>0.8)$ in all cases, which is consistent with the high local statistical significance in Fig. 3. We conclude that the model's midlatitude response to the large SST anomalies in the Pacific is very robust [a similar conclusion for strong ENSO events was drawn by Hoerling and Kumar (1997)] and that the influence of the smaller SST anomalies in the Indian Ocean is quite robust as well.

\section{c. Precipitation anomalies over the United States}

Figure 5 shows precipitation anomalies over the United States, northern Mexico, and southern Canada expressed as a percentage of normal from CMAP observations, the forecast, and the Pacific and Pacific+Indian experiments. The corresponding results for the tropical Pacific and global experiments are not shown as they are very similar to those for the Pacific and Pacific + Indian, respectively. The shaded regions in Figs. 5bd correspond to anomalies that are statistically significant at the $90 \%$ level. Note that this is a lower threshold for significance than was used in the analysis of 700$\mathrm{hPa}$ height anomalies.

Figure 5a shows that conditions were wetter than normal along much of the west coast and most of the eastern half of the United States with the largest departures from normal over northern California and Florida. The pattern of anomalous precipitation along the West Coast is typical of that observed during strong El Niños (Barnston

$\leftarrow$

FIG. 3. Mean 700-hPa geopotential height anomalies (m) for the period Jan-Mar 1998 from (a) NCEP reanalysis, (b) the forecast experiment, (c) the tropical Pacific experiment, (d) the Pacific experiment, (e) the Pacific+Indian experiment, and (f) the global experiment. Contour interval is $20 \mathrm{~m}$ (zero contour omitted), negative values are shown with dashed contours, and shaded areas denote anomalies that are significant at the $99 \%$ level. 

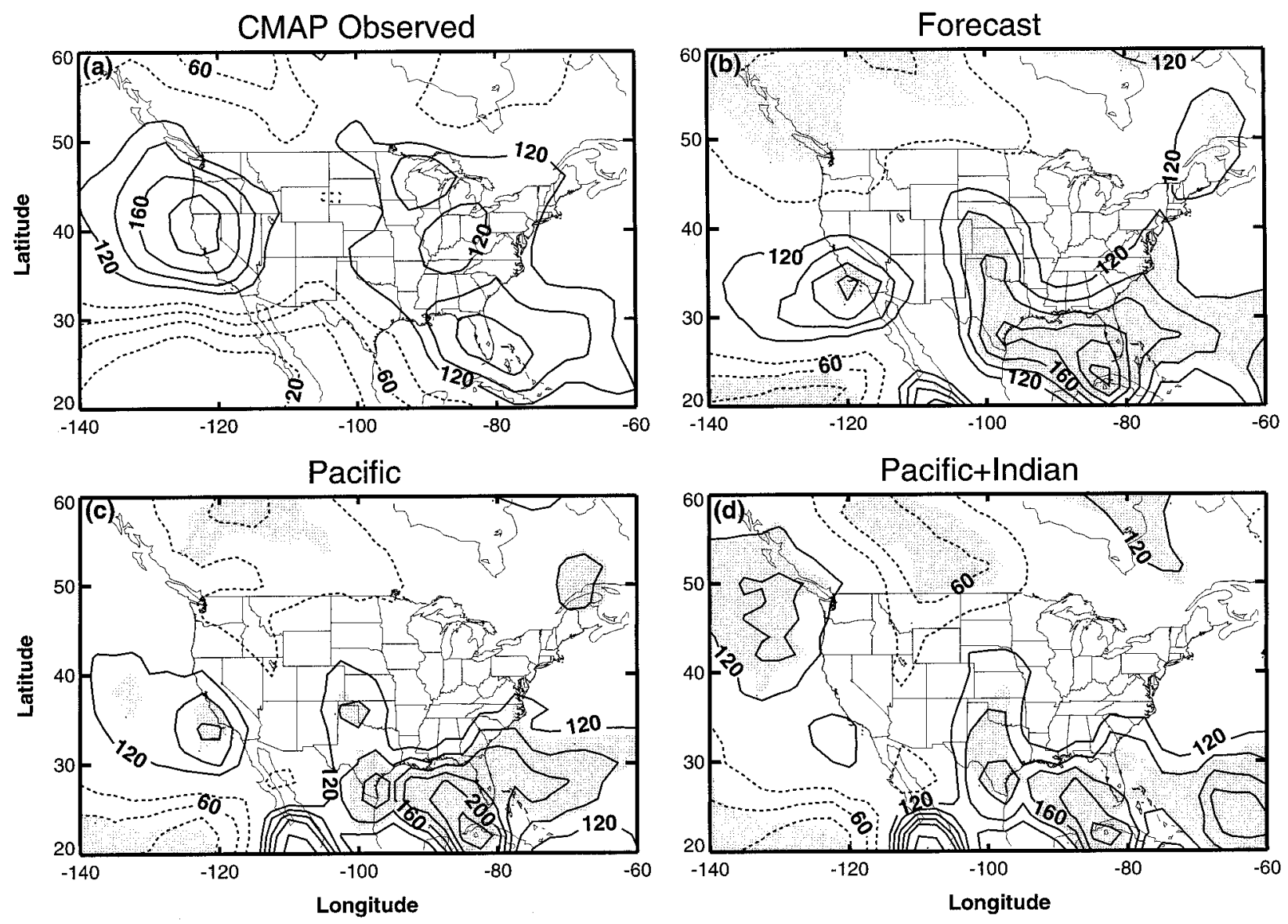

FIG. 5. Percentage of normal precipitation averaged over the period Jan-Mar 1998 as determined from (a) NCEP-NCAR reanalysis data, (b) the forecast experiment, (c) the Pacific experiment, and (d) the Pacific +Indian experiment. Contour interval is $20 \%$, values less than $100 \%$ are shown with dashed contours, and shaded areas denote anomalies that are significant at the $90 \%$ level.

et al. 1999; Hoerling and Kumar 2000). This pattern differs from that typically observed during weak to moderate strength El Niños in which the anomalously wet conditions are confined to California (Schonher and Nicolson 1989). Conditions were drier than normal across most of Canada and nearly all of northern Mexico.

Each of the experiments (Figs. 5b-d) produces regions of excess precipitation in the east and southeast United States, though in each the region covered by above normal precipitation is more confined to the deep South and extends farther west (into Texas/northern Mexico) than observed. Over large areas of the southeastern United States and the Gulf of Mexico these positive departures are statistically significant and their maximum amplitude is within $40 \%$ of the observed. Each of the experiments also produces a region of above normal precipitation somewhere along the West Coast. In the forecast and Pacific experiments (Figs. 5b and $5 \mathrm{c}$ ), above normal precipitation is found only in California with the largest departures in southern California. This pattern of anomalies resembles observed composites for weak to moderate El Niño events (Schonher and
Nicolson 1989). In the Pacific+Indian experiment (Fig. 5d), the positive departures over land are smaller and the largest departures are found offshore of Washington and Oregon. In all experiments, the maximum amplitude of these departures is within $40 \%$ of the observed. It should be noted that these West Coast anomalies are mostly not statistically significant at the $90 \%$ level. In the forecast and Pacific experiments, only small areas in southern California and western Canada show statistically significant positive departures, while there is a somewhat larger region of significant positive departures offshore of the Pacific Northwest in the Pacific+Indian experiment. Thus, though there are differences in the simulated anomalous precipitation patterns along the West Coast when Indian Ocean SST anomalies are included, these differences are not statistically significant over land. We note that the simulated anomalies in the southeastern United States/Gulf of Mexico are less affected by the inclusion of Indian Ocean SSTs.

\section{Discussion}

We have demonstrated in the previous sections of this paper that in our model simulations the inclusion SST 
anomalies over the Indian Ocean produces a statistically significant difference in the response over $700-\mathrm{hPa}$ heights to El Niño over the North Pacific and western North America. Midlatitude SST anomalies, on the other hand, have a less robust and statistically insignificant impact. In this section, we examine from two different points of view the differences between experiments that include and those that exclude Indian Ocean SST anomalies.

\section{a. Intrinsic modes of variability}

Here we determine how much of the model's midlatitude response to tropical SST anomalies can be accounted for by intrinsic modes of low frequency $(10<$ $T<100$ days) variability. The latter can be extracted empirically from the probability density function (PDF) of within-ensemble variability using 10-day lowpassfiltered daily geopotential height maps. Local maxima, or bumps, in the PDF correspond to regimes of recurrent and persistent height patterns in physical space that characterize the atmosphere's intrinsic intraseasonal modes of variability (Kimoto and Ghil 1993a,b). Tropical heating anomalies driven by SST anomalies are hypothesized to influence the triggering of the atmosphere's intrinsic modes, rather than leading to distinct modes (Legras and Ghil 1985; Horel and Mechoso 1988; Palmer 1999). This implies changes in the frequency of occurrence of regimes rather than their spatial structures.

Four regimes were diagnosed over the North PacificNorth American sector from the within-ensemble model variability; details of the method are given in the appendix. The dataset used here is 36 winters of daily $700-\mathrm{hPa}$ height maps from the 18 control members and the 9-member tropical Pacific and Pacific+Indian experiments. The latter two experiments were chosen as representative of the types of mean responses seen in Fig. 3.

Figure 6 shows composite hemispheric maps of daily 700-hPa height anomalies for the sets of days belonging to each regime. Regimes 1 and 2 loosely form a pair of opposite polarities, with a strong anomaly center over the Gulf of Alaska, extending over northern Canada and the Arctic. A broad, weaker anomaly center of the opposite polarity is located over the northwest Pacific. Regimes 3 and 4 both exhibit a deepened Aleutian low, and a weak downstream ridge centered over central North America and Alaska, respectively. Regimes 2-4 have clear counterparts in analyses of observed data using the same technique, while regime 1 has no obvious observed counterpart (Robertson and Ghil 1999). Quite similar looking composite anomalies were derived from a clustering of the control ensemble alone (not shown).

The circulation regimes are similar in pattern to the ensemble mean responses in Fig. 3 in certain cases. For example, regime 4 is highly correlated with the response obtained in the Pacific experiment $(r=0.92)$ while regime 1 is highly correlated that in the Indian $(r=$ 0.88), and to a lesser extent with that in the Pacific +Indian $(r=0.57)$ ensemble mean response. These correlations were computed for the region $20^{\circ}-70^{\circ} \mathrm{N}$, $120^{\circ} \mathrm{E}-60^{\circ} \mathrm{W}$.

Figure 7 describes intraseasonal variability in terms of the frequency of occurrence of the four regimes in days per winter. The four regimes occur with rather similar frequency in each experiment, indicating that within-ensemble variability is scarcely affected by the prescribed SST anomalies. In addition, we wish to test the hypothesis that the differences in mean response between the experiments (i.e., Fig. 3) can be accounted for by changes in regime frequency. To do so, Fig. 8 shows the regime's frequency of occurrence with all geopotential height anomalies defined with respect to the mean of the control ensemble (see appendix for details). In this case, the Pacific+Indian experiment is characterized by a much higher occurrence of regime 1 and a smaller increase in the occurrence of regime 3, compared to Fig. 7. In contrast, the tropical Pacific experiment shows an almost twice-greater increase in the occurrence of regime 4 plus a smaller increase in the occurrence of regime 3 . We note that the total number of days in Fig. 8 that fall into a regime is 1607, compared to the 1460 days classified in Fig. 7; thus, the intrinsic regimes do appear to characterize well the mean response to SST anomalies. The bar-length differences shown in Fig. 7 can be interpreted as a conservative measure of random sampling variations. By this measure, the large differences in bar length in Fig. 8 are unlikely to be due to sampling errors.

To further test the extent to which the ensemble mean responses in Fig. 3 can be interpreted in terms of the model's intrinsic weather regimes, Fig. 9 shows response patterns derived solely from the regime composites in Fig. 6. Here, each pattern has been weighted by its relative change in frequency between the CONTROL and forced experiment (Fig. 8). The patterns do compare reasonably well with Fig. 3, with pattern correlations over the Pacific-North American sector $\left(20^{\circ}-\right.$ $70^{\circ} \mathrm{N}, 120^{\circ} \mathrm{E}-60^{\circ} \mathrm{W}$ ) of $r=0.74$ (tropical Pacific) and $r=0.65$ (Pacific+Indian) demonstrating the relevance of the model's intrinsic modes of variability. The amplitudes in the regime response composites, however, are quite severely underestimated. This indicates that tropical forcing does influence the amplitude of the regimes, as well as their frequency of occurrence. This result is consistent with the observed weather regime study of Kimoto and Ghil (1993a), which found that amplitude varies much more than spatial pattern.

Regime composites of 200-hPa streamfunction and divergence have been constructed analogous to Fig. 6 (not shown). Spatially coherent divergence anomalies are mostly confined to midlatitudes, suggesting that the regimes do not owe their existence to tropical forcing on intraseasonal timescales. 
REGIME 1

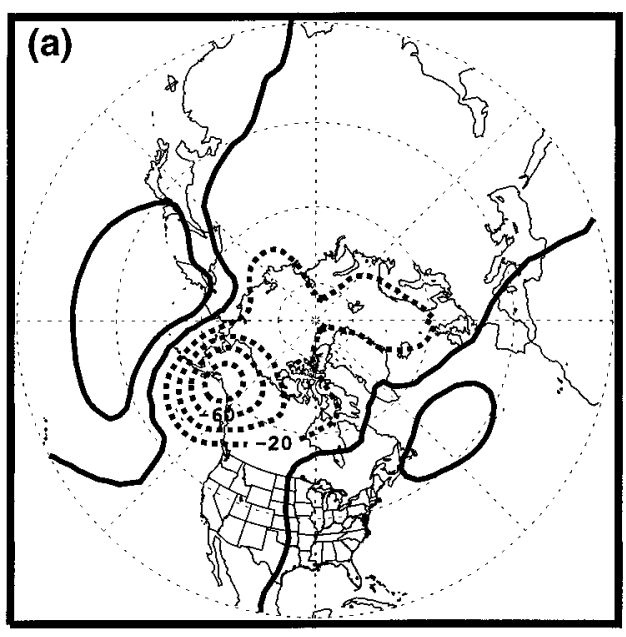

REGIME 3

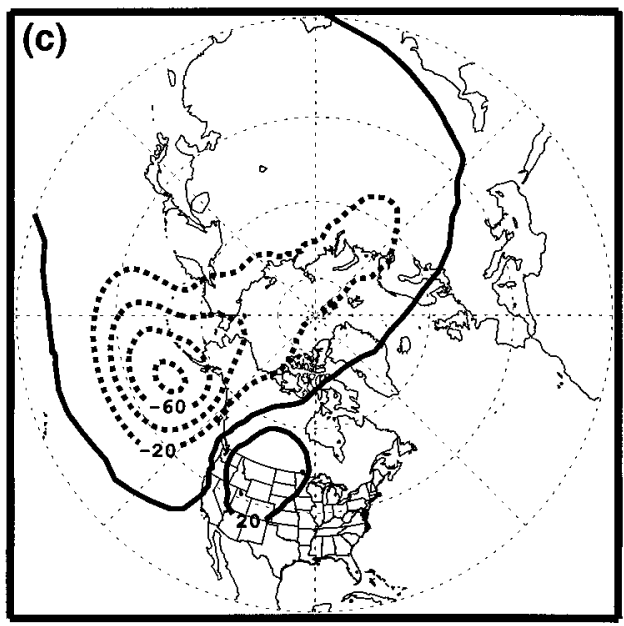

REGIME 2

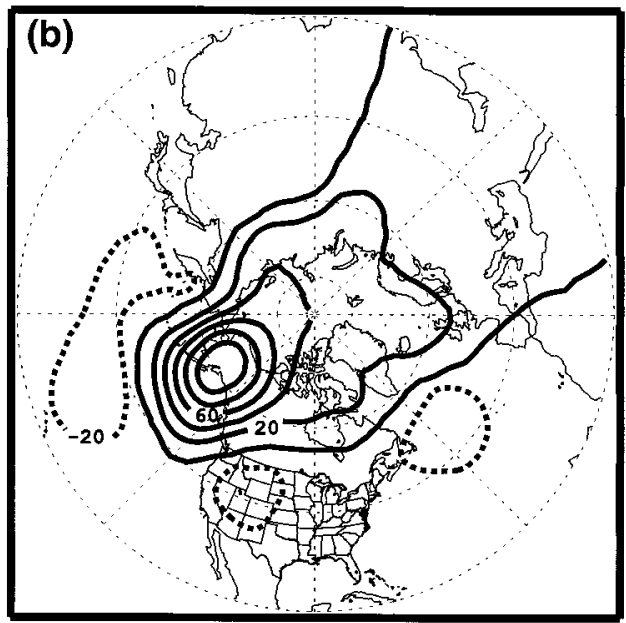

\section{REGIME 4}

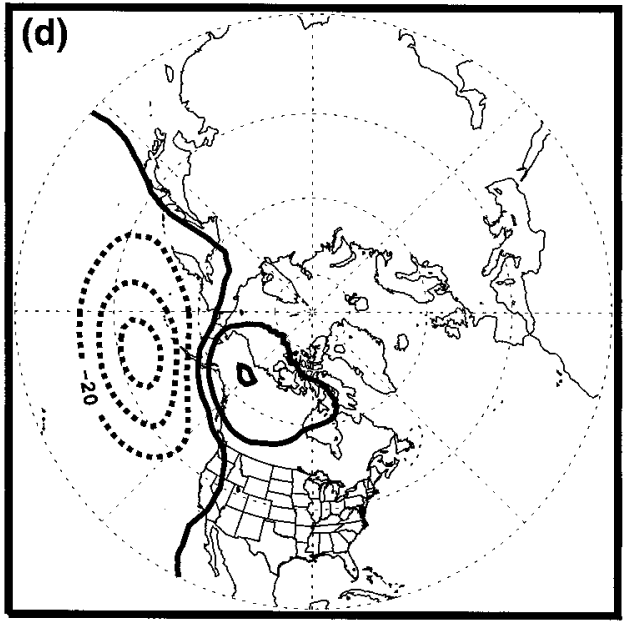

FIG. 6. Composite hemispheric maps of daily 700-hPa height anomalies $(\mathrm{m})$ for the sets of days belonging to each intraseasonal weather regime. The contour interval is $20 \mathrm{~m}$ and negative values are shown with dashed contours. The number of days in each regime is $413,362,352$, and 333, respectively. Note that the regimes were derived only using North Pacific-North American sectorial data.

\section{b. Linear response}

In this section, we consider the linearity of the response, defined by the usual difference in ensemble means. The mean $700-\mathrm{hPa}$ response patterns in Figs. 3 and 4 suggest that the response in the Pacific+Indian experiment can be interpreted as the sum of the responses in the Pacific and Indian experiments. To examine this apparent linearity further, we plot in Fig. 10 the JFM 200-hPa streamfunction anomalies. In the Pacific experiment (Fig. 10a), twin upper-level anticyclones straddle the equator near the longitude of maximum equatorial precipitation anomalies at about $150^{\circ} \mathrm{W}$. This configuration is typical of the atmospheric response to El Niño-like tropical heating anomalies (e.g., Horel and Wallace 1981). There is some indication of poleward propagation over the North Pacific and North America, although the pattern does not resemble the great circle Rossby wave train seen in simplified models (Hoskins and Karoly 1981). The Indian response (Fig. 10b) exhibits a similar anticyclonic pair near $60^{\circ} \mathrm{E}$ - the longitude of maximum tropical precipitation anomalies in the Indian Ocean - and a wavelike pattern downstream over the Pacific that arches over North America and into the Atlantic. Figures 10c and 10d display the difference between the anomalies in Pacific+Indian and Pacific experiments (Fig. 6c) and between the observed and the Pacific experiment (Fig. $10 \mathrm{~d})$. There is a high degree of correspondence between 
Regime Occurrence

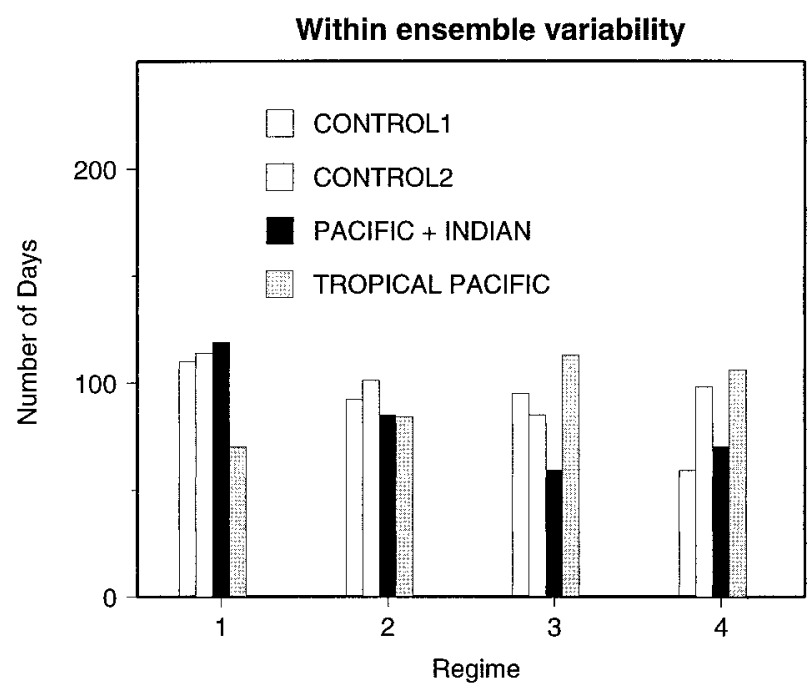

FIG. 7. Frequency of weather regime occurrence (days) in the control, tropical Pacific, and Pacific + Indian experiments for within-ensemble variability only (see text). Note that the 18-member control ensemble has been separated into two 9-member ensembles for comparison with the 9-member tropical Pacific and Pacific+Indian ensembles.

Figs. 10c and 10d as evidenced by the high pattern correlation of $r=0.83$ between them for the region $\left(20^{\circ}-70^{\circ} \mathrm{N}, 30^{\circ}-310^{\circ} \mathrm{E}\right)$.

Ting and $\mathrm{Yu}$ (1998) examined the impact of heating anomalies at various longitudes in linear and nonlinear baroclinic models. Their results for heatings centered at $120^{\circ} \mathrm{W}$ and $60^{\circ} \mathrm{E}$ resemble those of our Pacific and Indian experiments, respectively. Nonlinear effects were

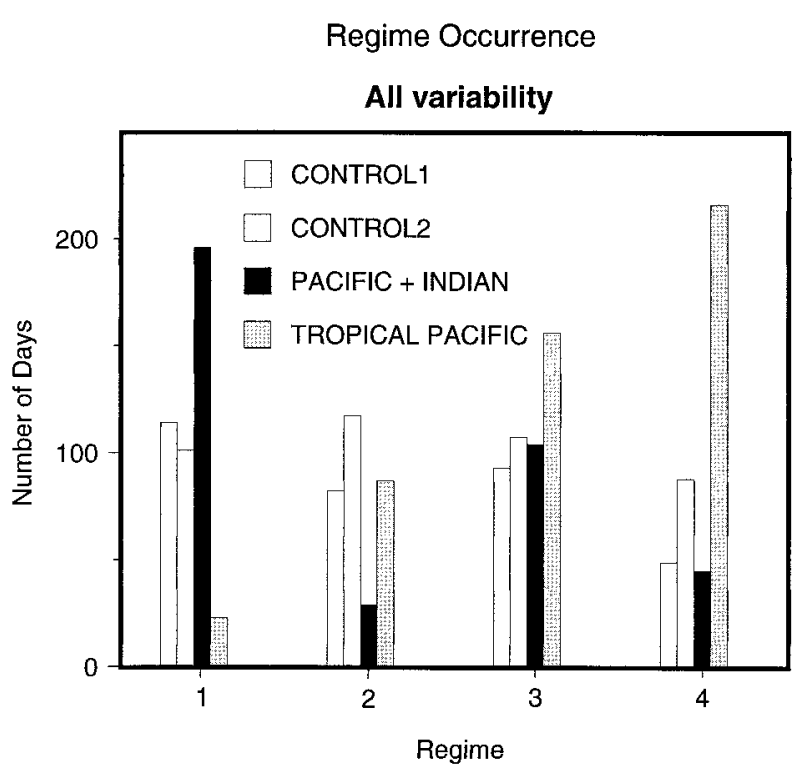

FIG. 8. As in Fig. 10 except for all variability, including betweenexperiment differences (see text).

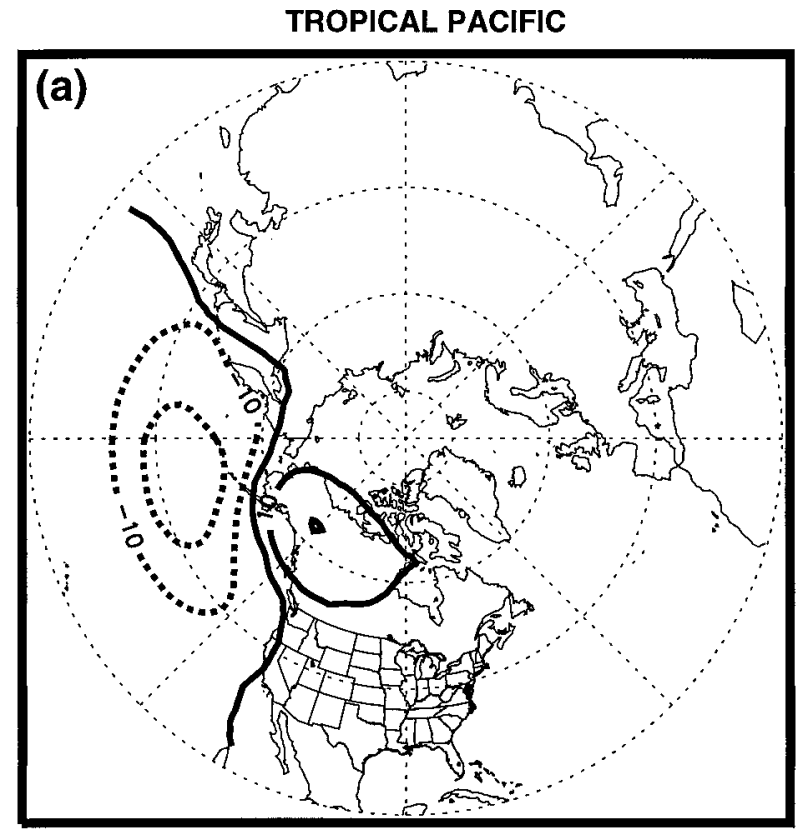

PACIFIC+INDIAN

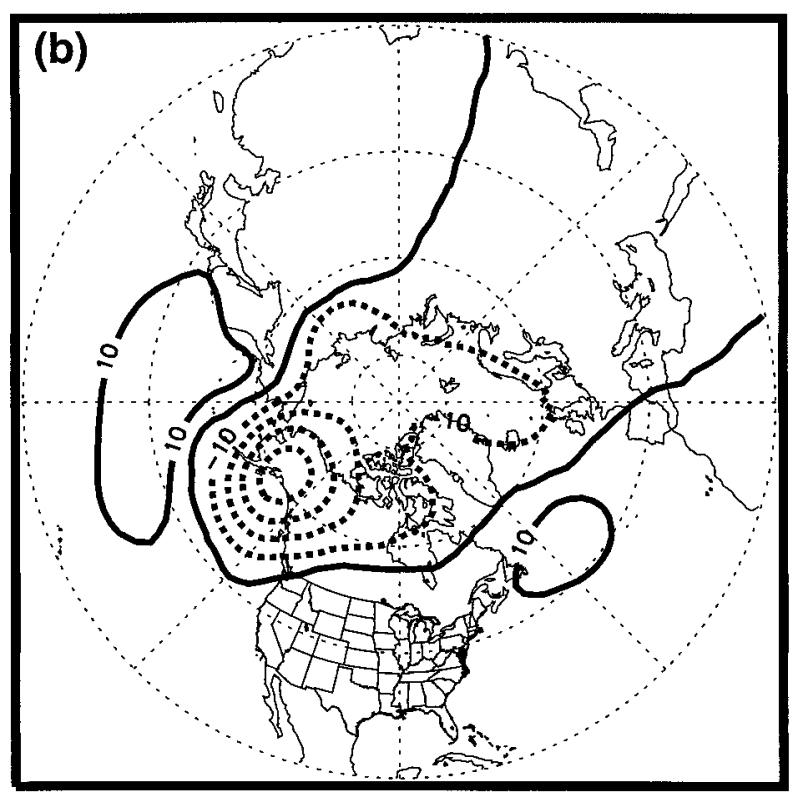

FIG. 9. Composite hemispheric maps of daily 700-hPa height anomalies (m) for the sets of days belonging to each of the intraensemble regimes weighted by the relative change in frequency between the control and (a) tropical Pacific and (b) Pacific +Indian experiments shown in Fig. 11. The contour interval is $10 \mathrm{~m}$ and negative values are shown with dashed contours.

found to be secondary, although the influence of anomalous transient eddies was not considered. Support for such a linear interpretation is given by the resemblance of Fig. 11 (which shows the 700-hPa JFM 1998 geopotential height anomalies from the Indian experiment) to Fig. 4 (the difference in $700-\mathrm{hPa}$ height anomalies, 


\section{Pacific}

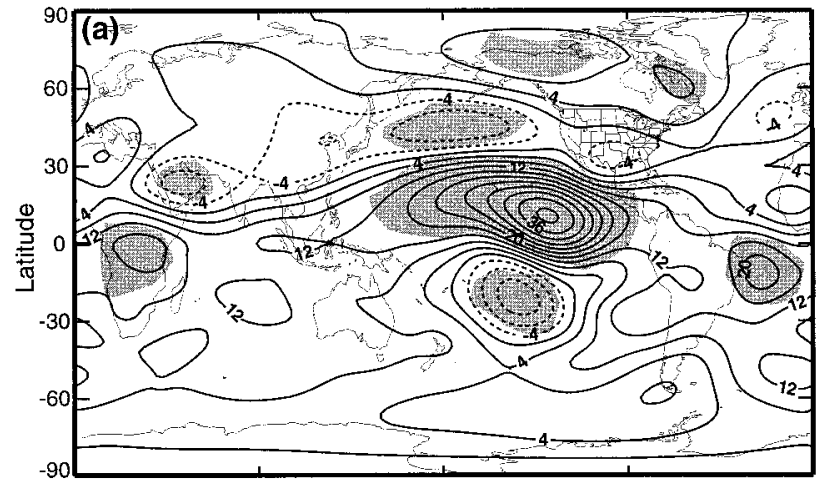

(Pacific+Indian) - Pacific

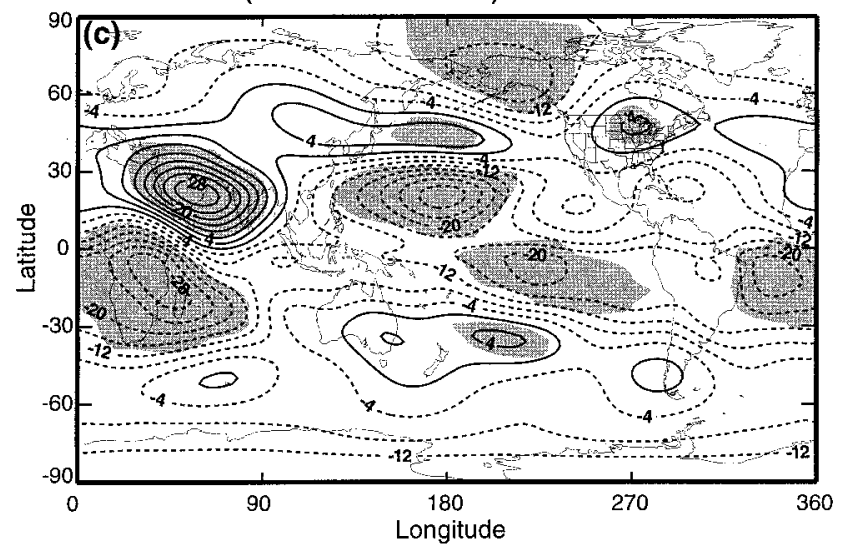

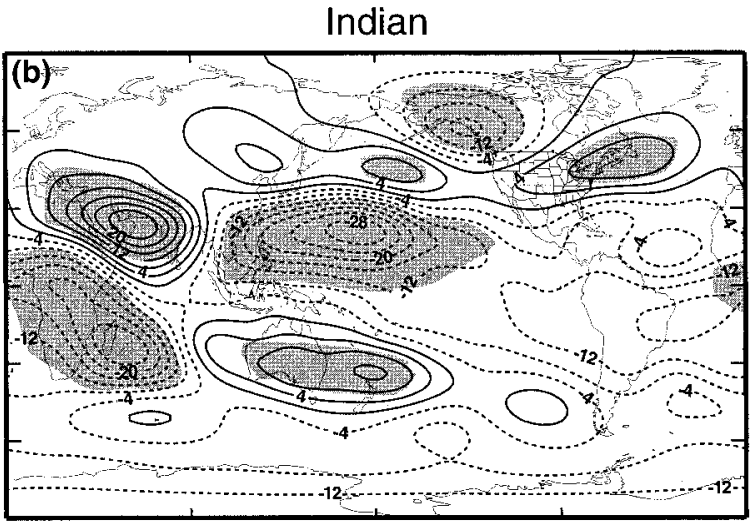

Observed - Pacific

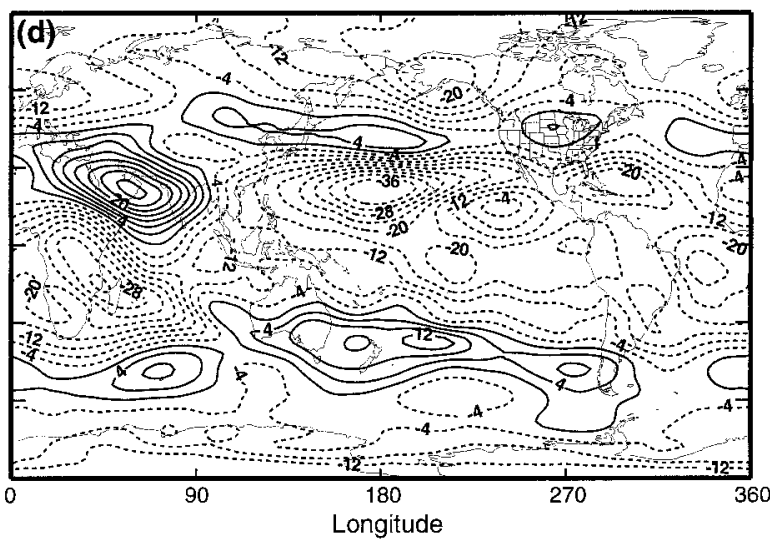

FIg. 10. Jan-Mar 1998 mean 200-hPa streamfunction $\left(10^{6} \mathrm{~m}^{2} \mathrm{~s}^{-1}\right)$ : (a) anomalies from the Indian ensemble, (b) anomalies from the Pacific experiment, (c) the difference between anomalies obtained from the Pacific +Indian (P+I) experiment and those from the Pacific experiment, and (d) the difference between observed (NCEP reanalysis) anomalies and those from the Pacific experiment. The contour interval is $4 \times$ $10^{6} \mathrm{~m}^{2} \mathrm{~s}^{-1}$ (zero contour omitted) and negative values are shown with dashed contours.

Pacific +Indian minus Pacific), the pattern correlation between the two maps over the same region used in Table 1 is $r=0.82$. Further, the similarities between Figs. 10c (Pacific+Indian minus Pacific) and 10d (observed minus Pacific) indicate that the same sort of wave train seen in the Indian experiment (Fig. 10b) was present in the real atmosphere during this time. This suggests that the overestimate of the local response in precipitation to Indian Ocean SST anomalies in the Pacific+Indian experiment (see Fig. 2e) did not result in a serious overestimate of their impact on the extratropics.

In order to better understand why this might be so, we examine the "Rossby wave source," $\mathcal{S}$, as defined by Sardeshmukh and Hoskins (1988). This is a diagnostic relevant to the extratropical atmospheric response to tropical SST anomalies:

$$
\mathcal{S}=-\mathbf{v}_{\chi} \cdot \boldsymbol{\nabla}\left(\boldsymbol{\nabla} \times \mathbf{v}_{\psi}+f \hat{\mathbf{k}}\right)-\left(\boldsymbol{\nabla} \times \mathbf{v}_{\psi}+f \hat{\mathbf{k}}\right)\left(\boldsymbol{\nabla} \cdot \mathbf{v}_{\chi}\right),
$$

where the velocity, $\mathbf{v}$, has been written in terms of its rotational and divergent components $\left(\mathbf{v}_{\psi}\right.$ and $\mathbf{v}_{\chi}$, re- spectively) and $f$ is the Coriolis parameter. As Sardeshmukh and Hoskins (1988) emphasized, the area that acts as a source of Rossby waves in the presence of tropical heating does not generally coincide with the region where the heating takes place. In fact, the largest values of the Rossby wave source are typically in the subtropics rather than the Tropics due to the much stronger vorticity gradients in the vicinity of the subtropical jet.

These features are present in Fig. 12, which shows anomalies in $\mathcal{S}$ at $200 \mathrm{hPa}$ for JFM 1998 from the observations (Fig. 12a), as well as the Indian, Pacific, and Pacific+Indian experiments (Figs. 12b,c,d, respectively). The observations (Fig. 12a) show that there were two primary regions, indicated by negative maxima in the field (dashed contours) on the equatorward flank of the subtropical jet in the Northern Hemisphere, that acted as anomalous sources of Rossby waves during this period. One region was over northern Africa and extended eastward into the Indian Ocean, the other was centered near Hawaii. Both of these regions are remote 


\section{Indian}

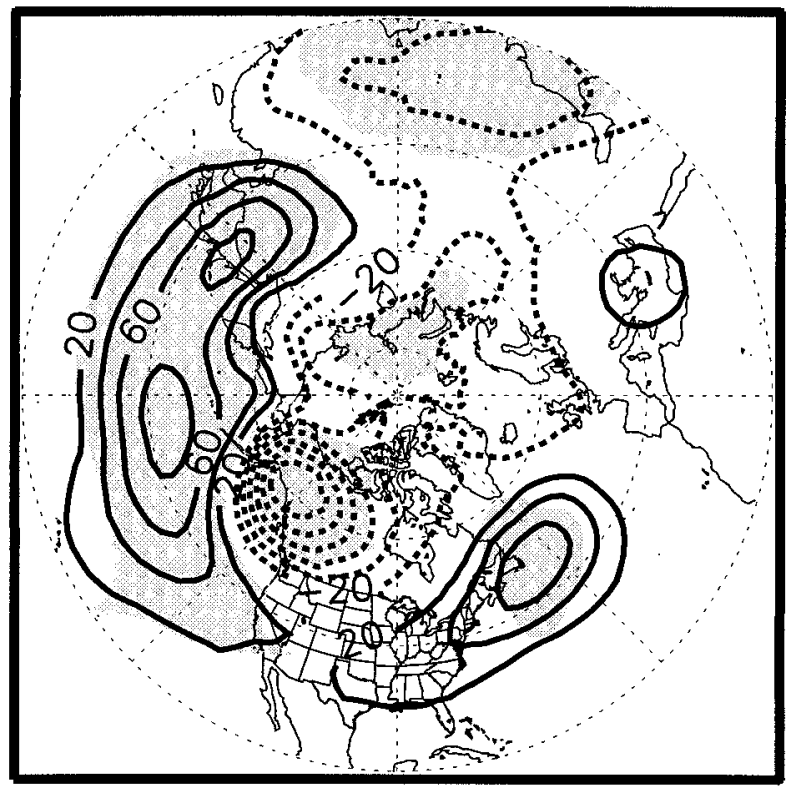

FIG. 11. As in Fig. 4 except for the Indian experiment.

from the regions of anomalous divergent outflow (not shown) associated with anomalous tropical precipitation, which in both the Indian and Pacific Oceans are located very near, or somewhat south of, the equator. In between these negative anomaly centers is a positive one centered just south of Japan associated with indirect effects.

In the Pacific+Indian experiment (Fig. 12d), there are also two primary negative anomaly centers, one over northern Africa extending eastward and the other in the central Pacific centered just south of Hawaii. The Indian (Fig. 12b) and Pacific (Fig. 12c) experiments each show one of those primary anomalous source regions. The positive anomaly center appears only in experiments (see Figs. 12b and 12d) that include Indian Ocean SST anomalies. The largest anomalies in $S$ have approximately the same magnitude as the observed, which are in the $10-15 \times 10^{-11} \mathrm{~s}^{-2}$ range. Simulated anomalies in $\mathcal{S}$ are somewhat overestimated over northern Africa and slightly underestimated in the central Pacific. More precisely, since it is the area-integrated value of $S$ that is most relevant to the impact on the extratropics, we have computed the differences between Figs. 12a and $12 \mathrm{~d}$ in these area-averaged values for the anomaly center in the Indian sector $\left(10^{\circ}-30^{\circ} \mathrm{N}, 20^{\circ}-80^{\circ} \mathrm{E}\right)$. We find that the values are larger than observed in the Pacific + Indian experiment by a factor of 1.75 . The model does have too much forcing, nevertheless, the area-averaged $\left(10^{\circ} \mathrm{S}-10^{\circ} \mathrm{N}, 20^{\circ}-80^{\circ} \mathrm{E}\right)$ tropical precipitation anomalies in the Indian sector are overestimated by a considerably greater factor (3.1). Thus, although precipitation anomalies (Fig. 2e) and upper-tropospheric divergence anom- alies (not shown) in the tropical Indian Ocean are both substantially overestimated in the Pacific+Indian experiment, the overestimate in the associated anomalous Rossby wave source in the subtropics is considerably smaller. An inspection of the 200-mb vorticity field from the Control experiment (not shown) shows that the model underestimates meridional gradients of vorticity on the equatorward flank of the subtropical jet. Such an underestimate would reduce the magnitude of the anomalous Rossby wave source in this region. The overall picture that emerges from this analysis is one in which the differences between the Pacific and Pacific + Indian experiments can be understood in terms of the linear superposition of a Rossby wave train emanating from the Indian Ocean. In support of this conclusion we offer the following: the similarity of Fig. 11 to Fig. 4, the resemblance of Fig. 10c to Fig. 10b, and the fact that in Fig. 12 we see that the two primary centers of anomalous Rossby wave forcing found in observations and the Pacific+Indian experiment appear in isolation in the Pacific and Indian experiments.

\section{Conclusions}

The response of the extratropical winter circulation to SST anomalies has been analyzed through atmospheric general circulation model two-tier predictions and simulations using the 1997-98 winter as a case study. Ensembles of simulations and predictions were performed using different distributions of SST anomalies as lower boundary conditions. We found that the extratropical circulation in the North Pacific-North American sector is significantly different if SST anomalies over the Indian Ocean are included. The SST anomalies in the western Indian Ocean during this winter were the largest of record and were accompanied by large positive precipitation anomalies. On the other hand, while small differences in the structure and evolution of tropical SSTs anomalies in the Pacific had a substantial impact on the simulated precipitation anomalies in the Tropics, their impact on the midlatitude circulation was small. In addition, there was no detectable atmospheric signal associated with extratropical SST anomalies.

The different extratropical responses found in simulations that include Indian Ocean SSTAs compared to those that do not were interpreted in terms of a linear superposition of a Rossby wave train emanating from the subtropical Indian Ocean region. By comparing observed and simulated $200-\mathrm{hPa}$ streamfunction anomalies, we argued that the modeled impact of the Indian Ocean SST anomalies on the extratropical circulation was realistic.

We have also examined the extratropical response to SST anomalies in terms of their influence on the model's intrinsic modes of intraseasonal variability via a PDF analysis of $700-\mathrm{hPa}$ height anomalies. The results strongly suggest that the model's modes of intrinsic var- 

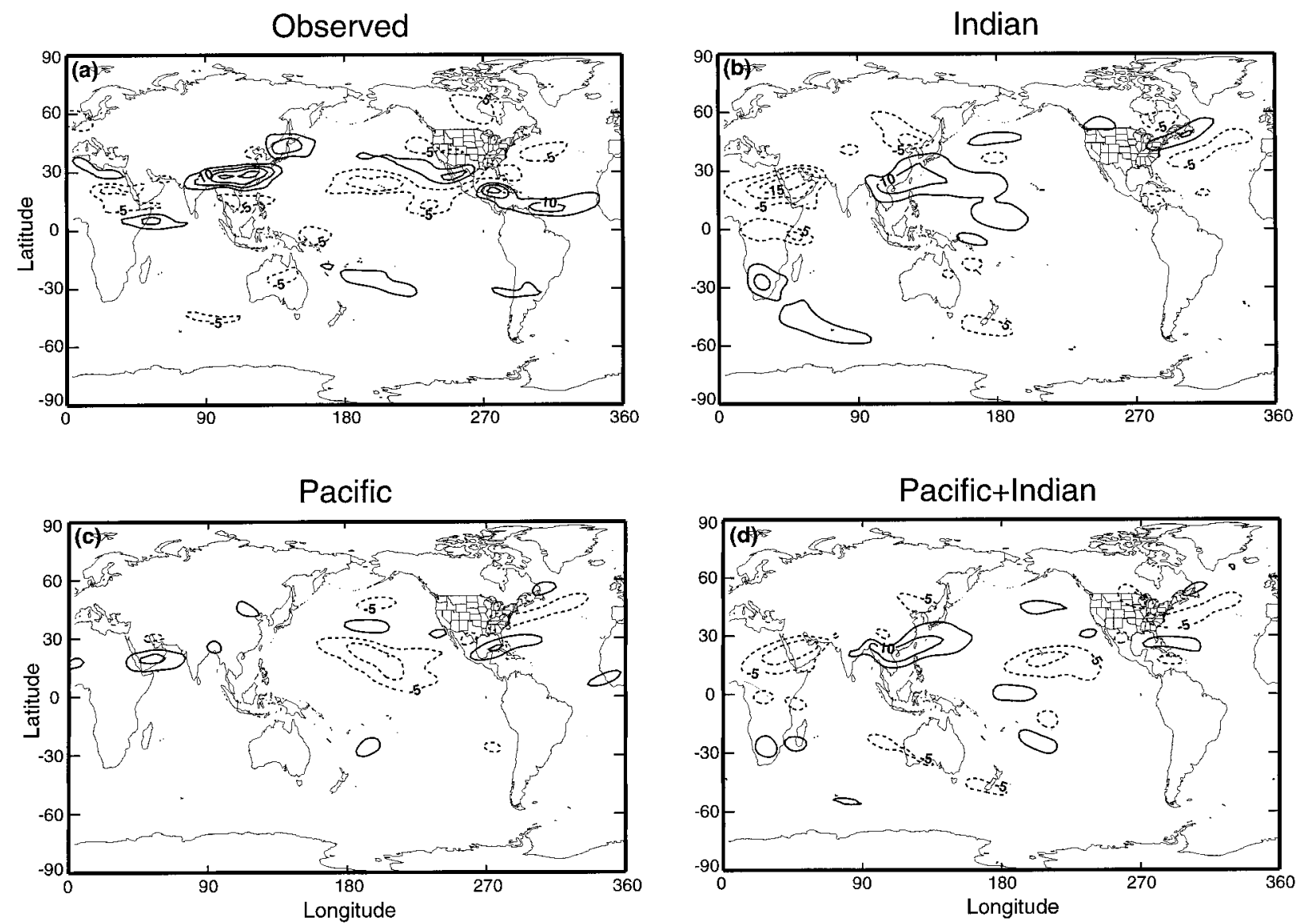

FIG. 12. Jan-Mar 1998 mean 200-hPa anomalous Rossby wave source, $S\left(\mathrm{~s}^{-2}\right)$ from (a) the NCEP reanalysis, (b) the Indian experiment, (c) the Pacific experiment, and (d) the Pacific+Indian experiment. The contour interval is $5 \mathrm{~s}^{-2}$ (zero contour omitted) and negative values are shown with dashed contours.

iability are involved in the mean response to SSTs and that the tropical SST anomalies influence the frequency of occurrence of these modes. Furthermore, they suggest that the tropical forcing influences the amplitude of the intrinsic modes as well as their frequency of occurrence.

Our basic conclusion is that Indian Ocean SST anomalies can impact the northern winter extratropical circulation at least in the particular winter chosen for case study (1997-98). The limitation to a single year does not allow us to make any general comments on the impact of the Indian Ocean on the northern winter circulation. However, our findings provide an important counterexample to those of Kumar and Hoerling (1998), who found that, in general, the inclusion of SST anomalies in the Indian Ocean degraded their simulations of the extratropical northern winter circulation. They attributed this to the fact that the modeled tropical precipitation anomalies in the Indian Ocean were poorly simulated, being unrealistically highly correlated with local SST anomalies. In 1997-98, observed Indian Ocean precipitation anomalies are fairly well correlated with SST anomalies and our simulations suggest that these have a statistically significant impact on the ex- tratropics. As with any modeling study, we must note the possibility that our results might be model-dependent. Concerning this possibility, we again note the correspondence between Figs. 6c and 6d, which suggests that our model simulations are producing realistic results.

Goddard and Graham (1999) have already demonstrated the importance of tropical Indian SSTAs for simulating rainfall anomalies over eastern and southern Africa. Together with our results, this provides motivation for operational centers to provide SST forecasts for the entire Tropics.

Acknowledgments. We thank Arun Kumar and two anonymous reviewers for their constructive comments on an earlier version of the manuscript, which resulted in its substantial improvement. Financial support for this work was provided by the NASA High Performance Computing and Communications for Earth and Space Sciences (HPCC-ESS) project under CAN 21425/041, by the National Science Foundation under Grant ATM9630226 and by the National Oceanic and Atmospheric Administration under Grant NA76-GP0536, and the 
California Centers for Water and Wildland Resources under Project W-918. AWR's work is supported by DOE Grant DE-FG03-98ER62615. Computer resources were provided by the NASA Office of Mission to Planet Earth, Aeronautics and Space Sciences. The NCEPNCAR reanalysis data was provided by the NOAACIRES Climate Diagnostics Center, Boulder, Colorado, from their Web site (http://www.cdc.noaa.gov/).

\section{APPENDIX}

\section{Weather Regime Methodology}

To construct the weather regimes, within-ensemble variability was first isolated for each experiment by (i) lowpass filtering at 10 days (Blackmon and Lau 1980) and (ii) subtracting the ensemble mean seasonal cycle of the respective experiment on a daily basis, subsequent to the lowpass filtering. Weather regimes were then derived from the PDF of a 36-winter daily dataset of 700$\mathrm{hPa}$ geopotential height maps over the North PacificNorth American sector $\left(20^{\circ}-70^{\circ} \mathrm{N}, 120^{\circ} \mathrm{E}-60^{\circ} \mathrm{W}\right)$. Here the period 1 December 1997-31 March 1998 was selected to increase the sample size. Likewise, the dataset of the 18 control members was concatenated together with the 9-member tropical Pacific and Pacific+Indian ensembles to obtain a large enough sample for density estimation (Silverman 1986; Kimoto and Ghil 1993a,b).

Following the method of Kimoto and Ghil (1993b), the PDF was constructed in the subspace of the leading four EOFs of the 36-winter filtered dataset, using a kernel density estimator and an angular metric in which length corresponds to pattern correlation between height fields in physical space. This estimator provides a tradeoff between smoothness and robustness to subsampling of the PDF, on the one hand, and fidelity to the data, on the other. The angular metric emphasizes differences in spatial pattern rather than amplitude. A kernel smoothing parameter of $h=40^{\circ}$ was chosen subjectively, yielding four local density maxima; an iterative bump-hunting method was then used to locate these maxima, which correspond to the centroids of the circulation regimes (Kimoto and Ghil 1993b).

Daily maps are assigned to a regime if they have a pattern correlation of 0.82 or greater with the central map; this membership criterion yields negligible overlap between clusters and assigns 1460 out of 4104 days $(36 \%)$ to regimes. The leading four covariance EOFs account for $63 \%$ of intraensemble variance. The use of a higher-dimensional EOF subspace is impractical with the length of dataset available (Silverman 1986). However, similar regime patterns were obtained by repeating the analysis using the $K$-means clustering method as applied by Michelangeli et al. (1995), in which clusters are constructed in the subspace of the leading 10 EOFs. The frequency of occurrences of the four regimes identified are not found to vary systematically over the December-March season.
The frequency of occurrence of each regime is given by the number of days per winter spent in that regime, as defined by the above pattern correlation criterion between anomaly maps of geopotential height. In Fig. 7, anomalies are defined with respect to the ensemble mean seasonal cycle of each individual experiment separately (i.e., control, tropical Pacific, and Pacific+Indian). In Fig. 8, on the other hand, all anomalies are defined with respect to the ensemble mean seasonal cycle of the control experiment. To determine the regime membership of each day for Fig. 8, the anomaly maps were projected into the original four-dimensional EOF subspace and daily maps assigned to the regime centroids in the same way as before. Thus, in Fig. 8, we test how much of the ensemble mean response can be accounted for by the model's intrinsic regimes.

\section{REFERENCES}

Arakawa, A., and W. H. Schubert, 1974: Interaction of a cumulus ensemble with the large-scale environment, Part I. J. Atmos. Sci., 31, 674-701.

Atlas, R., N. Wolfson, and J. Terry, 1993: The effect of SST and soil moisture anomalies on GLA model simulations of the 1988 U.S. summer drought. J. Climate, 6, 2034-2048.

Barnett, T. P., and R. Preisendorfer, 1987: Origins and levels of monthly and seasonal forecast skill for United States surface air temperatures determined by canonical correlation analysis. Mon. Wea. Rev., 115, 1825-1850.

— anomalies. Tellus, 46, 381-397.

Barnston, A. G., and R. E. Livezey, 1987: Classification, seasonality and persistence of low-frequency atmospheric circulation patterns. Mon. Wea. Rev., 115, 1083-1126.

- and Coauthors, 1999: NCEP forecasts of the El Niño of 199798 and its U.S. impacts. Bull. Amer. Meteor. Soc., 80, 18291852.

Bengtsson, L., U. Schlese, E. Roeckner, M. Latif, T. P. Barnett, and N. Graham, 1993: A two-tiered approach to long-range climate forecasting. Science, 261, 1026-1029.

Blackmon, M. L., and N.-C. Lau, 1980: Regional characteristics of the Northern Hemisphere winter time circulation: A comparison of the simulation of a GFDL general circulation model with observations. J. Atmos. Sci., 37, 497-514.

Brankovic, C., T. N. Palmer, and L. Ferranti, 1994: Predictability of seasonal atmospheric variations. J. Climate, 7, 217-237.

Branstator, G., 1985: Analysis of general circulation model sea surface temperature anomaly simulations using a linear model. Part II: Eigenanalysis. J. Atmos. Sci., 42, 2242-2254.

, 1992: The maintenance of low-frequency atmospheric anomalies. J. Atmos. Sci., 49, 1924-1945.

Chiba, M., K. Yamazaki, K. Shibata, and Y. Kuroda, 1996: The description of the MRI atmospheric spectral GCM (MRI-GSPM) and its mean statistics based on a 10-year integration. Pap. Meteor. Geophys., 47, 1-45.

Deser, C., and M. L. Blackmon, 1993: Surface climate variations over the North Atlantic Ocean during winter: 1900-1989. J. Climate, 6, 1743-1753.

Ferranti, L., F. Molteni, and T. N. Palmer, 1994: Impact of localized tropical and extratropical SST anomalies in ensembles of seasonal GCM integrations. Quart. J. Roy. Meteor. Soc., 120,16131645.

Gershunov, A., and T. P. Barnett, 1998: Interdecadal modulation of ENSO teleconnections. Bull. Amer. Meteor. Soc., 79, 27152725.

Goddard, L., and N. E. Graham, 1999: Importance of the Indian Ocean 
for simulating rainfall anomalies over eastern and southern Africa. J. Geophys. Res., 104, 19 099-19 116.

Graham, N. E., T. P. Barnett, R. Wilde, U. Schlese, and L. Bengtsson, 1994: On the roles of tropical and midlatitude SSTs in forcing interannual to interdecadal variability in the winter Northern Hemisphere circulation. J. Climate, 7, 1416-1441.

Harshvardhan, R. Davies, D. A. Randall, and T. G. Corsetti, 1987: A fast radiation parameterization for atmospheric circulation models. J. Geophys. Res., 92, 1009-1016.

—, D. A. Randall, T. G. Corsetti, and D. A. Dazlich, 1989: Earth radiation budget and cloudiness simulations with a general circulation model. J. Atmos. Sci., 46, 1922-1942.

Held, I. M., S. W. Lyons, and S. Nigam, 1989: Transients and the extratropical response to El Niño. J. Atmos. Sci., 46, 163-174.

Hoerling, M. P., and A. Kumar, 1997: Why do North American climate anomalies differ from one El Niño event to another? Geophys. Res. Lett., 24, 1059-1062.

- and A. Kumar, 2000: Understanding and predicting extratropical teleconnections related to ENSO. El Niño and the Southern Oscillation: Multiscale Variations, Global and Regional Impacts, H. F. Diaz and V. Markgraf, Eds., Cambridge Press, in press.

Horel, J. D., and J. M. Wallace, 1981: Planetary-scale atmospheric phenomena associated with the Southern Oscillation. Mon. Wea. Rev., 109, 813-829.

— sonal variability of the wintertime planetary circulation. $\mathrm{J}$. Climate, 1, 582-599.

Hoskins, B., and D. Karoly, 1981: The steady linear response of a spherical atmosphere to thermal and orographic forcing. $J$. Atmos. Sci., 38, 1179-1196.

Ji, M., A. Kumar, and A. Leetmaa, 1994: A multiseason climate forecast system at the National Meteorological Center. Bull. Amer. Meteor. Soc., 75, 569-577.

_ D. W. Behringer, and A. Leetmaa, 1998: An improved coupled model for ENSO prediction and implications for ocean initialization. Part II: The coupled model. Mon. Wea. Rev., 126, 1022 1034.

Kalnay, E., and Coauthors, 1996: The NCEP/NCAR 40-Year Reanalysis Project. Bull. Amer. Meteor. Soc., 77, 437-471.

Kimoto, M., and M. Ghil, 1993a: Multiple flow regimes in the Northern Hemisphere winter. Part I: Methodology and hemispheric regimes. J. Atmos. Sci., 50, 2625-2643.

$\longrightarrow$, and -1993 b: Multiple flow regimes in the Northern Hemisphere winter. Part II: Sectorial regimes and preferred transitions. J. Atmos. Sci., 50, 2645-2673.

Kirchner, I., G. L. Stenchikov, H. F. Graf, A. Robock, and J. C. Antuna, 1998: Climate model simulation of winter warming and summer cooling following the 1991 Mount Pinatubo volcanic eruption. Max-Planck-Institut fur Meteorologie Rep. 261, 35 pp.

Klein, S. A., B. J. Soden, and N.-C. Lau, 1999: Remote sea surface temperature variations during ENSO: Evidence for a tropical atmospheric bridge. J. Climate, 12, 917-932.

Kumar, A., and M. P. Hoerling, 1995: Prospects and limitations of seasonal atmospheric GCM predictions. Bull. Amer. Meteor. Soc., 76, 335-345.

- , and -1997 : Interpretation and implications of the observed inter-El Niño variability. J. Climate, 10, 83-91.

— , and — 1998: Specification of regional sea surface temperatures in atmospheric general circulation model simulations. $J$. Geophys. Res., 103, 8901-8907.

Latif, M., and T. P. Barnett, 1994: Causes of decadal climate variability over the North Pacific and North America. Science, 266, 634-637.

Lau, N.-C., 1997: Interactions between global SST anomalies and the midlatitude atmospheric circulation. Bull. Amer. Meteor. Soc., 78, 21-33.

Legras, B., and M. Ghil, 1985: Persistent anomalies, blocking and variations in atmospheric predictability. J. Atmos. Sci., 42, 433471.

Li, J.-L., and A. Arakawa, 1997: Improved simulation of PBL moist processes with the UCLA GCM. Preprints, Seventh Conf. on Climate Variations, Long Beach, CA, Amer. Meteor. Soc., 3540.

Mechoso, C. R., J.-Y. Yu, and A. Arakawa, 2000: A coupled GCM pilgrimage: From climate catastrophe to ENSO simulations. General Circulation Model Development: Past, Present and Future. Proceedings of a Symposium in Honor of Professor Akio Arakawa, D. A. Randall, Ed., Academic Press, in press.

Michelangeli, P.-A., R. Vautard, and B. Legras, 1995: Weather regimes: Recurrence and quasi-stationarity. J. Atmos. Sci., 52, 1137-1256.

Murphy, A. H., and E. S. Epstein, 1989: Skill scores and correlation coefficients in model verification. Mon. Wea. Rev., 117, 572581.

Palmer, T. N., 1999: A nonlinear dynamical perspective on climate prediction. J Climate, 12, 575-591.

— , and D. L. T. Anderson, 1994: The prospects for seasonal forecasting-A review paper. Quart. J. Roy. Meteor. Soc., 120, 755793.

Pan, D.-M., and D. A. Randall, 1998: A cumulus parameterization with a prognostic closure. Quart. J. Roy. Meteor. Soc., 124, 949981.

Rayner, N. A., C. K. Folland, D. E. Parker, and E. B. Horton, 1995: A new global sea-ice and sea surface temperature (GISST) data set for 1903-1994 for forcing climate models. Wadley Centre Internal Note 69, U.K. Met. Office, 14 pp.

Reynolds, R. W., and T. M. Smith, 1995: A high resolution global sea surface temperature climatology. J. Climate, 8, 1571-1583.

Robertson, A. W., and M. Ghil, 1999: Large-scale weather regimes and local climate over the western United States. J. Climate, 12, 1796-1813.

_ C. R. Mechoso, and Y.-J. Kim, 2000: The influence of Atlantic SST anomalies on the North Atlantic oscillation. J. Climate, 13, $122-138$.

Saravanan, R., 1998: Atmospheric low frequency variability and its relationship to midlatitude SST variability: Studies using the NCAR Climate System Model. J. Climate, 11, 1386-1404.

Sardeshmukh, P. D., and B. J. Hoskins, 1988: The generation of global rotational flow by steady idealized tropical divergence. J. Atmos. Sci., 45, 1228-1251.

Schonher, T., and S. E. Nicholson, 1989: The relationship between California rainfall and ENSO events. J. Climate, 2, 1258-1269.

Silverman, B. W., 1986: Density Estimation for Statistics and Data Analysis. Chapman and Hall, 175 pp.

Suarez, M. J., A. Arakawa, and D. A. Randall, 1983: The parameterization of the planetary boundary layer in the UCLA general circulation model: Formulation and results. Mon. Wea. Rev., 111, $2224-2243$.

Sud, Y. C., G. K. Walker, and W. E. Smith, 1991: Analysis of a general circulation model simulation of the atmospheric response to the observed sea surface temperature anomalies of January and February 1983. J. Climate, 4, 107-115.

Ting, M., and P. D. Sardeshmukh, 1993: Factors determining the extratropical response to equatorial diabatic heating anomalies. J. Atmos. Sci., 50, 907-918.

_ linear and nonlinear baroclinic models. J. Atmos. Sci., 55, 35653582.

Tourre, Y. M., and W. B. White, 1995: ENSO signals in global upperocean temperature. J. Phys. Oceanogr., 25, 1317-1332.

Wallace, J. M., and D. S. Gutzler, 1981: Teleconnections in the geopotential height field during the Northern Hemisphere winter. Mon. Wea. Rev., 109, 784-811.

Xie, P., and P. A. Arkin, 1997: Global precipitation: A 17-year monthly analysis based on gauge observations, satellite estimates and numerical model outputs. Bull. Amer. Meteor. Soc., 78, 25392558. 